\title{
Kevin Carson como o Médico e o Monstro*
}

\author{
Walter Block ${ }^{* *}$
}

\begin{abstract}
Resumo: Neste ensaio, o autor elabora uma análise crítica da obra Studies in Mutualist Political Economy, de Kevin Carson. A crítica do autor concentra-se na adoção, por parte de Carson, da teoria do valor-trabalho como elemento fundamental de seu arcabouço teórico. Ademais, o autor expõe diversos conceitos equivocados de Carson a respeito de vários aspectos do libertarianismo.
\end{abstract}

Palavras-Chave: Mutualismo, Teoria do valor-trabalho, Libertarianismo.

\section{Kevin Carson as Dr. Jekyll and Mr. Hyde}

\begin{abstract}
In this essay, the author elaborates a critical analysis of the work Studies in Mutualist Political Economy, by Kevin Carson. The author's criticism centers around Carson's adoption of the labor theory of value as the fundamental element of his theoretical framework. Besides, the author exposes several misconceptions that Carson presents regarding many aspects of libertarianism.
\end{abstract}

Key words: Mutualism, Labor theory of value, Libertarianism.

Classificação JEL: A13, B53, P16.

\footnotetext{
* Artigo publicado originalmente em inglês como: BLOCK, Walter. Kevin Carson as Dr. Jekyll and Mr. Hyde. Journal of Libertarian Studies, Vol. 20, No 1 (Winter 2006): 35-46.

[O autor do artigo emprega os nomes "Dr. Jekyll" e "Mr. Hyde", numa referência ao famoso livro de Robert Louis Stevenson (1850-1894). Preferimos traduzi-los por "Médico" e "Monstro", por tratar-se de tradução já consagrada no Brasil (N. T.)].

Traduzido o original em inglês para o português por Davi J. Dias.
}

** Walter E. Block é Harold E.Wirth Eminent Scholar Endowed Chair e Professor de Economia da Escola de Negócios da Loyola University, em New Orleans.

E-mail: wblock@loyno.edu 
Studies in Mutualist Political Economy', de Kevin Carson, é um livro exasperante.

Por um lado, o autor demonstra grande familiaridade com muitos dos mais importantes colaboradores libertários ${ }^{2}$ no campo da política econômica. Em ordem alfabética de sobrenome, são eles: Eugen von Böhm-Bawerk (1851-1914), Art Carden, Sean Corrigan, Roger Garrison, Leonard Liggio (1933-2014), Roderick Long, Tibor Machan (1939-2016), Carl Menger (1840-1921), Ludwig von Mises (1881-1973), Albert J. Nock (1870-1945), Robert Nozick (1938-2002), Franz Oppenheimer (1864-1943), Murray Rothbard (1926-1995) ${ }^{3}$ e Jean-Baptiste Say (1767-1832).

Por outro lado, a familiaridade com esta lista de autores libertários parece ter sido desperdiçada por Carson, pois ele adota a teoria do valor-trabalho para todas as coisas como elemento fundamental de seu arcabouço teórico. E não apenas isso. Poder-se-ia talvez perdoar alguém que não é economista por se deixar seduzir pelo canto da sereia marxista da teoria do valor-trabalho. Ocorre que o autor também está completamente enganado a respeito de numerosos princípios do libertarianismo, que ele ataca com despreocupada ignorância. Ora, considerando que os dois componentes principais da economia política são, naturalmente, a política e a economia, e que Carson não oferece nenhuma contribuição real a nenhum deles, é difícil não dizer que seu livro é tudo, menos útil. Uma pena, pois é claro que muito trabalho e esforço foram gastos para escrevê-ló. Alguém poderia achar que Carson, por ter tamanha familiaridade com tais autores, não poderia errar tanto em seus pensamentos sobre economia política. Seria um grande engano.

${ }^{1}$ CARSON, Kevin A. Studies in Mutualist Political Economy. Publicação do autor. Fayetteville, Ark, 2004. Disponível em: <http://mutualist.org/id47.html>.

${ }^{2}$ É uma redundância.

${ }^{3}$ Carson cita não menos do que nove publicações de Rothbard.

${ }^{4}$ Mais um indício da fragilidade da teoria do valortrabalho.
E ainda, por outro lado (sim, existe um terceiro lado), a familiaridade de Carson com a economia política libertária é tão ampla e profunda $^{5}$ que parte desta, pelo menos, ele já assimilou. Em longos trechos do livro isto é demonstrado pelo autor, que até apresenta contribuições originais (falarei mais sobre isso adiante). Minha avaliação geral do livro é que foi escrito por um "Médico e Monstro" esquizofrênico: quando é bom, é muito, muito bom; quando é ruim, é de fato terrível.

Exemplos concretos?

Comecemos com a sua defesa da teoria do valor-trabalho, seu principal erro e fonte de grande parte de suas recomendações perniciosas e disparatadas no campo das políticas públicas. Nos dias de hoje, se alguém considera seriamente essa doutrina ou, ainda mais, tenta defendê-la, é como aceitar uma opinião que tivesse sido rejeitada amplamente e corretamente, como a teoria da Terra plana ou a do flogístico. É, numa palavra, medieval.

${ }^{5}$ A maioria das críticas à Escola Austríaca provêm daqueles cujo conhecimento do campo é mínimo (p. ex., TULLOCK, Gordon. Why the Austrians Are Wrong About Depressions. Review of Austrian Economics, Vol. 2 (1987): 73-78.; para uma réplica, ver SALERNO, Joseph T. Comment on Tullock's 'Why Austrians Are Wrong About Depressions'. Review of Austrian Economics, Vol. 3 (1989): 141-45.). O livro que estamos a criticar é uma exceção. Para outra exceção, ver CAPLAN, Bryan. Probability and the Synthetic A Priori: A Reply to Block. Quarterly Journal of Austrian Economics, Vol. 6, No. 3 (2003): 77-83; CAPLAN, Bryan. Probability, Common Sense, and Realism: A Reply to Hülsmann and Block. Quarterly Journal of Austrian Economics, Vol. 4, No. 2 (2001): 69-86; e CAPLAN, Bryan. The Austrian Search for Realistic Foundations. Southern Economic Journal, Vol. 65, No. 4 (1999): 823-38.; entre outros, apresentam réplicas: HÜLSMANN, Jörg Guido. Economic Science and Neoclassicism. Quarterly Journal of Austrian Economics, Vol. 2, No. 4 (1999): 3-20; BLOCK, Walter. Austrian Theorizing, Recalling the Foundations: Reply to Caplan. Quarterly Journal of Austrian Economics, Vol. 2, No. 4 (1999): 21-39; BLOCK, Walter. Realism: Austrian vs. Neoclassical Economics, Reply to Caplan. Quarterly Journal of Austrian Economics, Vol. 6, No. 3 (2003): 63-76; e BLOCK, Walter. Rejoinder to Caplan on Bayesian Economics. Journal of Libertarian Studies, Vol. 19, No. 1 (2005): 79-95.; e BARNETT, William II. Contra Caplan. Manuscrito inédito. 
A sua conhecida refutação segue assim: se o trabalho, e apenas o trabalho, determina o valor de um objeto, que dizer do fato de que uma torta de cereja e um bolo de lama, feito por crianças, contêm o mesmo número de horas de trabalho, mas a primeira vale muito mais do que o segundo? A resposta do marxista ingênuo ${ }^{6}$ é que o que ele tem em mente não é o trabalho em si, mas o "trabalho socialmente necessário", ou algo semelhante. E, é claro, Carson ${ }^{7}$ cai exatamente na mesma armadilha, anzol, linha e chumbo de pesca. Mas definir "trabalho socialmente necessário" como aquele correlacionado ao valor (a torta de cereja tem mais do que o bolo de lama, que, afinal, não tem nenhum) é não explicar a sua origem. Por que é que a torta de cereja tem muito valor e o bolo de lama pouco ou nenhum? Poderia ser, talvez, que a torta de cereja contenha trabalho socialmente necessário e o bolo de lama não, porque as pessoas gostam de comer aquela, mas não este? É óbvio que isso é verdade. Mas, sendo assim, é argumentar em círculo, uma vez que jamais podemos saber o que é "socialmente necessário" e o que não é, enquanto não soubermos, e apenas se soubermos, quais são as preferências do consumidor - explicação essa bem diferente (e muito mais austríaca) de preço.

Uma segunda refutação da teoria do valor-trabalho deriva das considerações de tempo, risco e preferência temporal. A mão de obra é sempre livre para montar um estabelecimento por conta própria. $\mathrm{O}$ fato de não fazê-lo, ou seja, de contar com capitalistas para fazê-lo por ela, acaba por minar a opinião marxista de Carson, segundo a qual o capital explora a mão de obra.

O que o capital oferece à mão de obra? Primeiro, tempo. Leva tempo para construir uma fábrica, instalar o material em estado bruto, ter o seguro garantido, reunir mão de obra, montar as peças das máquinas em determinado local, etc. Durante todo esse tempo,

\footnotetext{
${ }^{6}$ Receio tratar-se de mais uma redundância.

${ }^{7}$ CARSON. Studies in Mutualist Political Economy, p. 38.
}

até que o primeiro produto final saia rolando da linha de montagem, o capital está pagando à mão de obra. Suponha que tal processo dure um ano inteiro. Se não fosse essa contribuição do capitalista, o trabalhador teria de viver de suas economias, hipotecar sua casa, vender seu carro, etc. Ele poderia fazer isso. Mas escolhe não fazê-lo. Antes, opta por fazer um negócio com o capitalista, para o bem do seu precioso tempo. Sem dúvida o capitalista merece algo em troca de sua contribuição, não importa qual seja o acordo entre ele e o trabalhador. E o que, em geral, se acorda é que o capitalista será o requerente do rendimento residual, ficando com tudo que sobrar depois que todos os fatores de produção - incluindo, é claro, a mão de obra - tiverem recebido a sua quota prevista no contrato.

Depois, também, existe um risco. Suponha que o produto não venda quando oferecido ao público. Absolutamente. Nem sequer um único item. Poderá o capitalista voltar-se para o trabalhador e dizer: "Lembra-se do dinheiro que lhe paguei por um ano de trabalho, enquanto você fazia o negócio funcionar? Pois bem, o artigo não vendeu; devolva-me os salários que lhe adiantei?" Como requerente do rendimento residual, o empresário não pode agir assim. É ele, e não o trabalhador, o portador dos riscos. A questão é: o empregado receberá, com certeza, o seu salário, e antes do fim da produção e da venda do produto. Mas o capitalista terá de esperar para ser recompensado, ainda que esse processo não termine dentro de um ano ou mais. Esse é o motivo por que o trabalhador aceita voluntariamente o acordo.

E qual a reação de Carson a essa espécie de análise böhm-bawerkiana ${ }^{8}$ ? Ele diz: "quando a mão de obra se abstém de consumir hoje para acumular seu próprio capital, a preferência temporal é somente uma forma a mais de desutilidade do trabalho presente, comparado ao trabalho futuro"

8 BÖHM-BAWERK, Eugen von. Capital and Interest. South Holland: Libertarian Press, 1884. (Ver particularmente Parte I, Capítulo XII: "Exploitation Theory of Socialism-Communism")

${ }^{9}$ CARSON. Studies in Mutualist Political Economy, p. 111. 
Não resolve absolutamente nada. Ora, de onde será que Carson pensa provirem, a princípio, os empresários capitalistas, senão da classe de artesãos que começam a trabalhar por conta própria, reduzem o consumo abaixo da renda e empregam as economias daí resultantes para financiar empregados no sistema de requerimento do rendimento residual? Não se pode negar, decerto, que alguns capitalistas começam com mão de obra usurpada no passado, como o autor afirma uma e outra vez - mas não é necessariamente o caso. Tirando isso, a resposta de Carson a Böhm-Bawerk soa-me incompreensível. Provavelmente, se ele tivesse uma resposta à crítica devastadora de Böhm-Bawerk ao socialismo, tê-la-ia exposto nesta altura do livro. Em vez disso, dedica insuficientes nove páginas ${ }^{10}$ para tratar rasamente deste ponto fundamental - e usando a maioria delas para citar os seus críticos.

A seguir, a análise econômica de Carson se deixa estragar por uma série de outros erros. Por exemplo ${ }^{11}$, ele junta ao conceito de lucro (este desaparece no equilíbrio) o de juro (não desaparece no equilíbrio). Vê a economia como um jogo de soma nula, em que o capitalista só pode ganhar à custa do trabalhador ${ }^{12}$. Parece não perceber que todas as interações comerciais, sobretudo aquela entre patrão e empregado, são, por necessidade, mutuamente benéficas no sentido ex ante, e, no que diz respeito à avassaladora realidade empírica, também no sentido ex post. Acredita na existência de algo como "socialismo de livre mercado"13, sem se dar conta de que é uma contradição em termos, se a expressão for empregada, como costuma ser, e como o próprio autor a usa, no sentido de despojar os capitalistas, os empresários, os proprietários de ter-

\footnotetext{
${ }^{10}$ Idem. Ibidem, p. 104-12.

${ }^{11}$ Idem. Ibidem, p. 15, p. 24.

${ }^{12}$ Idem. Ibidem, p. 14.

${ }^{13}$ Idem. Ibidem, p. 19.
}

ras, etc. do que lhes é de direito ${ }^{14}$. Carson aparenta não compreender que o "monopólio" implica, necessariamente, em interferências governamentais no acesso livre a uma indústria ${ }^{15}$. Pensa ${ }^{16}$ que o "lucro é fruto de uma troca desigual" (ora, me diga, que é isso?!). Sob certo ponto de vista, toda troca é igual, na medida em que ambas as partes ganham, no sentido ex ante; do contrário, dificilmente tomariam parte nela. Por outro lado, é desigual, na medida em que cada parte envolvida no negócio valoriza o que ganha mais do que aquilo de que abre mão. Mas, em sentido nenhum, há algo de sinistro relativamente à troca, apesar do que diz o autor. Ele repete esse erro sobre a troca desigual várias vezes ${ }^{17}$. Todavia, considera que "o capitalista age entre pessoas maiores e vacinadas", segundo a feliz terminologia de Nozick ${ }^{18}$, de maneira positiva, rejeitando corretamente o conceito de mercado como um jogo de soma nula. Não deixa de ser curioso como o autor é capaz de ser tão razoável em uma parte do livro e tão propenso a erros em outras.

Nosso autor cita Adam Smith (17231790) $)^{19}$ aprovativamente, com o propósito de dizer que "o 'preço real' das coisas [...] o que o objeto 'realmente custa para o homem que o deseja adquirir' foi 'o esforço e a fadiga que é necessário dispender para obtê-lo'"20. Mas imagine que eu

14 É claro que a expressão poderia muito bem ser utilizada para retratar a vida em comunidades formadas voluntariamente, cooperativas de trabalhadores voluntários, etc., mas estas não são mais do que parte integrante do sistema de livre iniciativa do capitalismo.

${ }^{15}$ CARSON. Studies in Mutualist Political Economy, p. 20.

${ }^{16}$ Idem. Ibidem, p. 22.

17 Por exemplo, em CARSON. Studies in Mutualist Political Economy, p. 115.

${ }^{18}$ NOZICK, Robert. Anarquia, Estado e Utopia. Rio de Janeiro: Jorge Zahar Editor, 1974. Cit. p. 163.

${ }^{19}$ SMITH, Adam. A Riqueza das Nações. São Paulo: Martins Fontes, 2003.

${ }^{20}$ CARSON. Studies in Mutualist Political Economy, p. 68. 
saia para dar uma volta e encontre um diamante gigantesco pousado numa rocha. Não preciso nem mesmo enfrentar "o esforço e a fadiga" de abaixar-me para pegá-lo, já que ele está bem ali, ao alcance da mão. Não faço mais que agarrá-lo. Na prática, não há nenhum "esforço e fadiga" envolvidos. E, no entanto, a pedra preciosa vale milhões.

Mais uma passagem. Carson escreve: "numa ordem de trocas livres e voluntárias, todas as transações são mutuamente benéficas para ambas as partes. É somente quando a força entra em cena que uma parte passa a se beneficiar à custa de outra" ${ }^{21}$. Tudo parece ir às mil maravilhas, pelo menos à primeira vista. A dificuldade surge quando nos damos conta de que, para o autor, a "força entra em cena" toda vez que um patrão faz uma oferta a um empregado. Para ele, trata-se de uma força (injustificada), pois o primeiro explora necessariamente o segundo. Considere, no entanto, a inversão da iniciativa, isto é, suponha que um patrão não faça propostas a um grupo de empregados. Ao contrário, o grupo de empregados é que inicia o contrato de emprego com o patrão, ao perceberem que são incapazes de abrir uma firma por conta própria; não querem arcar com os riscos e o tempo relativos ao empreendedorismo capitalista. Vamos deixar as coisas ainda mais complicadas para Carson. Suponha que o patrão A, a quem os empregados fazem essa proposta, fora ele mesmo um empregado; fora, com efeito, um deles. Mas ele, ao contrário dos demais, economizou um pouco de dinheiro, o suficiente para manter as coisas de pé por um ano, e está disposto a assumir o risco de ser funcionário. Carson abriria mão da tese de que o patrão explora, obrigatoriamente, os seus empregados? Se a resposta for sim, perde-se o núcleo de Studies in Mutualist Political Economy. Se for não, torna-se extremamente difícil entender o motivo por que deveríamos dar-lhe alguma atenção. É difícil responder a essa pergunta, já que Carson jamais considera tal hipótese.

\footnotetext{
${ }^{21}$ Idem. Ibidem, p. 131.
}

Como julgar o "fenômeno" Carson? Quero dizer, como conceber que um acadêmico, embora familiarizado intimamente com as obras de Mises, Böhm-Bawerk, Rothbard e muitos outros da tradição austro-libertária, os rejeite em absoluto? Não passa de uma especulação de minha parte, mas suponho que, apesar de Carson demonstrar grande familiaridade com essa literatura, é possível que ele nunca tenha se lançado nela na companhia de qualquer de seus proponentes. Isto é, ele é uma espécie de eremita intelectual; apenas leu o material referido, sem jamais ter se debatido com ele, de corpo e alma, como a maioria das pessoas só é capaz de fazer em diálogo com adeptos dessas ideias. Noutras palavras, ler é apenas parte do trabalho acadêmico. A interação pessoal, o debate, o diálogo são também necessários. O pequeno indício que tenho para essa opinião ${ }^{22}$ é que Carson chama seus adversários intelectuais de "miseanos", e não de "misesianos", que é o correto. Ninguém que tenha tido qualquer contato pessoal com defensores dessa perspectiva cometeria tal erro; mas o tenho ouvido, frequentemente, da boca daqueles cujo conhecimento do assunto resume-se à leitura de livros. Talvez seja só um erro tipográfico; do contrário, pode ter certo valor explicativo.

Sem dúvida, há lugares neste livro em que Carson acerta em cheio nas suas considerações. Em tais casos, a meu ver, ele é um rothbardiano completo e em boa forma. Por exemplo, sua magnífica desmistificação da pretensão de que "somos o governo" ${ }^{23}$. Além disso, a esplêndida análise da classe dirigente, na qual ele bebe dos insights de Murray Rothbard, Gabriel Kolko (1932-2014)24 e G. William

\footnotetext{
${ }^{22}$ Não conheço Carson pessoalmente. Não tenho a mínima ideia se ele alguma vez tratou em pessoa com rothbardianos. Os palpites que arrisco neste artigo são meras especulações.

${ }^{23}$ CARSON. Studies in Mutualist Political Economy, p. 135 .

${ }^{24}$ Idem. Ibidem, p. 231, p. 244.
} 
Domhoff ${ }^{25}$. Carson mostra igualmente estar em perfeita sintonia com muitas considerações libertárias bastante esotéricas, como o problema das patentes e o dos copyrights. Lê-se graciosamente na sua folha de rosto: "Fayetteville, Arkansas. Anti-copyright 2004. É permitido citar e reproduzir ilimitadamente" 26 .

Uma palavra sobre terminologia. Existem dois tipos de "capitalismo". Primeiro, o capitalismo monopolista do estado corporativo, ou fascismo econômico. Nesse contexto, as classes dirigentes são culpadas de todo tipo de exploração e violação. Refiro-me, claro, ao roubo puro e simples, não ao mero emprego de pessoas no sistema voluntário. Segundo, o anarcocapitalismo, ou capitalismo laissez-faire, em que, tirante o que marxistas como Carson consideram exploração dos trabalhadores por parte do patrão, tudo corre bem. A sociedade funciona segundo os axiomas libertários gêmeos dos direitos de propriedade (baseados na apropriação original e na troca voluntária) e da não agressão. A questão é que essas duas concepções de capitalismo são tão diferentes quanto o dia e a noite. Não têm nada em comum, salvo essa terminologia muitíssimo infeliz que rotula, a ambas, de "capitalismo". Qual a posição de Carson nessa questão? Será ele parte do problema, ao fundir os dois conceitos, ou parte da solução, ao traçar uma distinção clara entre os dois? Fazer essa pergunta é respondê-la, depois de se ter examinado cuidadosamente o seu livro. Como nesta altura já se pode esperar, o autor faz o que pode para causar confusão a esse respeito.

\footnotetext{
${ }^{25}$ Idem. Ibidem, p. 253. Infelizmente, a publicação não traz índice. Para apresentar o número das páginas nesta discussão, tive de folhear o livro inteiro. Verificase também certo desleixo em relação às notas de rodapé. Por exemplo, as notas 30 e 31, na página 208, aparentemente referem-se a Milton Friedman (19122006), mas o conteúdo na página 236 não o confirma.

${ }^{26}$ No entanto, ele se esquece de citar o magistral Kinsella nesta questão.Ver: KINSELLA, N. Stephan. Against Intellectual Property. Journal of Libertarian Studies, Vol. 15, No. 2 (2001): 1-53.
}

Por exemplo, ao denegrir a Mises por defender a revolução industrial ${ }^{27}$, a outros por apoiarem patrões de fábricas de trabalho pesado ${ }^{28}$ - cuja única culpa era oferecer salários mais altos do que os vigentes nas fazendas muitos séculos atrás, ou no mundo subdesenvolvido hoje. Carson o faz por pensar que esses patrões eram culpados por crimes os mais diversos. E talvez fossem. Mas a questão é irrelevante. É certo que Mises não defendia o roubo de terra ou quaisquer outras coisas de que Carson o acusa (para além da acusação de oferecer emprego segundo o sistema voluntário). Mises estava apenas defendendo os patrões enquanto patrões! E não é que Carson ignore por completo a distinção fundamental entre esses dois tipos muito diferentes de capitalismo ${ }^{29}$; daí a sua crítica a Mises e a outros autores constituir, talvez, uma confusão proposital e teimosa entre os dois tipos.

É claro que houve roubo de terras, como acusa Carson $^{30}$. Mas não deveria ser preciso lembrar-lhe de que isso é parte integrante do capitalismo monopolista do estado corporativo, não da sua variedade laissez-faire. Entre nós, alguns têm se esforçado por fazer essa distinção, principalmente para auxiliar analistas da América do Sul e da América Central, uma região do mundo que presenciou muito mais do que a sua partilha do roubo de terras. Esses analistas confundem amiúde as duas espécies de capitalismo, tão diferentes. Carson turva furiosamente as águas neste ponto, mesmo conhecendo bem a diferença.

\footnotetext{
${ }^{27}$ CARSON. Studies in Mutualist Political Economy, p. 140-143.

${ }^{28}$ N. do T.: Walter Block utiliza a expressão "sweat shop", que significa, literalmente, "loja de suor". O termo hoje é utilizado para se referir às fábricas que oferecem duras condições de trabalho, nos países em desenvolvimento.

${ }^{29}$ CARSON. Studies in Mutualist Political Economy, p. 144.

${ }^{30}$ Idem. Ibidem, p. 144-59.
} 
O modo como Carson trata a revolução industrial $^{31}$ é outro ponto relevante. Falha por completo em distinguir as duas variedades de capitalismo. Sim, é certo que houve, aqui e ali, roubo de terras, supressão e exploração. No entanto, por esse motivo, nosso autor joga fora o bebê da inovação junto com a água da repressão. Ora, podemos distinguir adequadamente entre o empreendedor que conduz a economia à modernidade e emprega crianças que doutra sorte morreriam de fome, ainda que a mesma pessoa também seja culpada de violar a lei libertária de não agressão.

A mesma coisa com a sua análise do comércio mundial ${ }^{32}$. $\mathrm{O}$ autor permite que os inegáveis abusos que às vezes ocorrem ponham em dúvida a justeza do comércio, da especialização e da divisão internacional do trabalho, per se. Escreve ele:

O "mercado mundial" moderno não foi criado por forças do livre-mercado. Como a produção capitalista na Europa ocidental, foi uma criação artificial do estado, imposta desde cima por uma revolução. O mercado mundial estabeleceu-se por meio da conquista europeia da maior parte do mundo e pela supremacia naval das potências da Europa ocidental. A intervenção estatal incentivou a manufatura destinada a servir a um mercado mundial, e isso com o fim de fechar as portas aos bens estrangeiros, conferir à marinha mercante europeia o monopólio do comércio exterior e acabar com a competição estrangeira à força ${ }^{33}$.

Respondo: É verdade, mas e daí? É verdade que no desenvolvimento do comércio mundial os dois tipos de capitalismo se misturaram. Daí vamos jogá-lo fora, por causa das violações de liberdade? De modo algum. Antes, tentamos, quando possível, fazer correções - e os culpados e seus herdeiros podem

\footnotetext{
${ }^{31}$ Idem. Ibidem, p. 159-69.

${ }^{32}$ Idem. Ibidem, p. 169-78.

${ }^{33}$ Idem. Ibidem, p. 169.
}

ser identificados ${ }^{34}$. Portanto, defendemos o comércio mundial, a revolução industrial, os investimentos estrangeiros em países subdesenvolvidos, as fábricas de trabalho pesado, etc. Não os atacamos por aquelas imperfeições a que estão associados historicamente, mas não necessariamente.

O mais decepcionante em relação a esses casos é que o autor é perfeitamente capaz de traçar as distinções necessárias:

A posição anarquista [...] é a de que a exploração e o domínio de uma classe não são, em nenhum momento, inevitáveis; dependem da intervenção estatal, que não é, de modo nenhum, necessária. Apenas as relações sociais e econômicas são compatíveis com qualquer nível tecnológico; o progresso técnico pode ser alcançado e novas tecnologias integradas à produção em qualquer sociedade, por meio do trabalho livre e da cooperação voluntária. Do mesmo modo, qualquer tecnologia é passível tanto de aplicações libertárias, quanto de aplicações autoritárias, a depender da natureza da sociedade à qual é incorporada ${ }^{35}$.

Mas, se é assim, por que culpar a revolução industrial? Isto é, por que culpar o episódio em si? Sim, ocorreram roubos e violações de diversos direitos durante esse período histórico. Mas o mesmo aplica-se a todos os eventos históricos. Podemos, com igual razão, rejeitá-los como à revolução industrial.

Que há com estes "proprietários de terras parasitários" ${ }^{36}$ ? Ou são culpados por uma ou outra espécie de roubo ou fraude - e assim são criminosos -, ou não o são - e assim ocupam lugar de honra entre os demais atores

34 BLOCK, Walter. On Reparations to Blacks for Slavery. Human Rights Review, Vol. 3, No. 4. (2002): 53-73; BLOCK, Walter \& YEATTS, Guillermo. The Economics and Ethics of Land Reform: A Critique of the Pontifical Council for Justice and Peace's 'Toward a Better Distribution of Land: The Challenge of Agrarian Reform'. Journal of Natural Resources and Environmental Law, Vol. 15, No. 1 (1999-2000): 37-69.

${ }^{35}$ CARSON. Studies in Mutualist Political Economy, p. 189.

${ }^{36}$ Idem. Ibidem, p. 206. 
econômicos na sociedade livre. Ou, mais provavelmente, alguns são culpados, outros não; ou a mesma pessoa é às vezes um proprietário de terras no sistema de livre iniciativa, outras vezes é um criminoso. Em tais casos, punimos os atos ilícitos e defendemos os lícitos. Todavia, o emprego dessa expressão coloca Carson bem no meio da esquerda. Estará ele disputando um cargo político em People's Republic of Santa Monica ${ }^{37}$, Ann Arbor ou Cambridge, Massachusetts?

Oponho-me à preferência de Carson pelos "rothbardianos de esquerda". Murray, verdade seja dita, aliou-se com a esquerda em certas ocasiões, quando pensou que assim promoveria mais a liberdade. Mas a mesma situação ocorre, também, com a direita. A sua filosofia, em contraste marcante com outras, tinha, por fio de prumo, o libertarianismo de ala política nenhuma (Block a ser publicado). Creio que Carson está tentando comparar a chamada ala esquerda do rothbardianismo com o capitalismo libertário, ou laissez-faire e, por extensão, o rothbardianismo de direita com o capitalismo monopolista do estado corporativo, ou fascismo. Mas isso violenta gravemente os fatos. Rothbard foi um libertário que não pertencia a nenhuma facção política; foi um anarquista austro-libertário.

Ao que parece, Carson tem algo de georgista $^{38}$ : "um retorno à terra [...] só poderia ocorrer

\footnotetext{
37 Santa Mônica é uma cidade costeira no oeste da região metropolitana da cidade de Los Angeles, Estados Unidos. Já foi chamada de People's Republic of Santa Monica, ou República do Povo de Santa Mônica, por causa de seus governos e políticas de esquerda. (N. T.)

38 Georgismo refere-se à teoria político-econômica elaborada pelo americano Henry George (18391897). O ponto central de seu pensamento é que as pessoas são proprietárias de tudo o que criam; bens naturais, como a terra, contudo, não deveriam possuir proprietários. O único imposto deveria ser aquele sobre a terra, que haveria de recair sobre os que possuíssem mais propriedades de terra. Embora George não fosse anarquista, alguns anarquistas assimilaram e reformaram o georgismo, transformando-o no chamado geoanarquismo. (N. T.)
}

por meio dos privilégios" 39 . Ocorre que a terra também está sujeita à boa ou à má administração. O sistema de livre iniciativa tende a tirá-la das mãos de quem a gerencia bem para colocá-la nas mãos de quem a gerencia mal. Não está claro por que uma crença rígida e inabalável na teoria do valor-trabalho havia de inclinar Carson, um suposto anarquista, à desaprovação do controle do empreendedor sobre a terra. Talvez - e aqui só podemos especular - a sua visão se fundamente no fato inegável de que houve mais do que apenas um pouco de roubo de terras na história. Mas isso de forma alguma justifica o roubo de terras, ainda maior, que consiste em tirar a terra das mãos de seus proprietários legítimos ${ }^{40}$. Para um remédio cem por cento eficaz contra a doença moral e intelectual do georgismo, ver Rothbard ${ }^{41}$.

Nosso autor perfilha a posição neoclássica convencional acerca do monopólio e da competição em face da correta posição da Escola Austríaca. De acordo com aquela, a existência ou não do monopólio ou da competição depende do número de sociedades comerciais existentes numa indústria; de acordo com esta, tudo depende de ser legal ou não o acesso livre. Carson caracteriza, como exemplo de capitalismo monopolista, "o surgimento de uma economia dominada por [...] indústrias em que relativamente poucas sociedades comerciais predominavam" ${ }^{42}$. Mas é um meio altamente competitivo, ainda quando nele atuam apenas duas "sociedades comerciais" - confor-

\footnotetext{
${ }^{39}$ CARSON. Studies in Mutualist Political Economy. p. 201.

${ }^{40}$ HOPPE, Hans-Hermann. The Economics and Ethics of Private Property: Studies in Political Economy and Philosophy. Boston: Kluwer, 1993.
}

${ }^{41}$ ROTHBARD, Murray N. A Reply to Georgist Criticisms. Irvington-on-Hudson: Foundation for Economic Education, 1957. p. 1-3. Reproduzido em: The Logic of Action Two: Applications and Criticism from the Austrian School. Cheltenham: Edward Elgar, 1997. p. 306-10.

${ }^{42}$ CARSON. Studies in Mutualist Political Economy. p. 240. 
me sabe muito bem qualquer pessoa que já esteve num ringue de boxe. Onde há uma só sociedade comercial que ofereça determinado serviço, já pode dar-se verdadeira competição. Por exemplo, a IBM e a Alcoa foram, por muitos anos, as únicas fornecedoras de computadores e alumínio, respectivamente. Ainda assim, é óbvio, não havia nenhuma lei que proibisse outros de entrar nessas indústrias e, afinal, outros acabaram por ingressar nelas. Verdade seja dita, a competição pode dar-se com zero competidor. Desde que a lei não proíba ninguém de fazer algo, haverá competição nesse setor. Por exemplo, no momento, ninguém oferece um produto que seja um combinado de peixe e bicicleta, ou pickles cobertos com chocolate. A competição, aqui, está completamente aberta. São indústrias competitivas, com zero competidor, porque não há lei que proíba ou limite a provisão de tais bens.

Mais uma vez, de maneira frustrante, Carson toma a correta via rothbardiana ${ }^{43}$ frente aos "randianos e Chicago Boys" 44 , em relação ao trust busting ${ }^{45}$. Essa iniciativa não foi tomada por mocinhos do governo preocupados em salvar os desafortunados consumidores das pilhagens dos empresários malvados. Ao contrário, o antitruste foi, e é, um conluio da parte dos empresários malvados para reduzir a competição; governos de homens malvados cooperaram nesse plano para enganar o povo. Será que o autor contradiz a si mesmo de propósito, apenas para me provocar?

\footnotetext{
${ }^{43}$ Idem. Ibidem, p. 243.

${ }^{44}$ Os Chicago Boys eram um grupo de jovens economistas chilenos, discípulos de Milton Friedman e da Escola de Chicago, que influenciaram nalgumas medidas políticas durante o governo do general Augusto Pinochet (1915-2006) que resultaram no chamado "milagre econômico chileno". (N. T.)

45 Atividades do governo que visam a acabar com trustes corporativos e monopólios. A origem da expressão remonta às leis antitruste promulgadas, nos Estados Unidos, no final do século XIX e início do XX. (N. T.)
}

Nessa veia, Carson ataca o "paternalismo" corporativo $^{46}$, em que as firmas oferecem aos trabalhadores, sob um sistema completamente voluntário ${ }^{47}$, coisas como habitação, pensões e outros benefícios secundários. Ora, me diga, que há de errado nisso? Por que o ordenado deveria ser pago somente em espécie? Qual o problema com pagamentos não pecuniários? Por que é ruim que os patrões instalem ar condicionado em seus estabelecimentos, pintem as paredes de cores bonitas, ofereçam música ambiente, etc.? Ainda que se faça uma concessão à opinião marxista de que pagar salário é uma forma de roubo, por que razão é um roubo adicional pagar parte do salário em remuneração não monetária?

Outro indício de que é bem superficial a compreensão de Carson sobre a distinção entre o capitalismo laissez-faire e o fascismo é que ele tacha instituições do capitalismo laissez-faire de "sarnas" 48 , "conluios" 49 , "liderança de preços" ${ }^{\prime 50} \mathrm{e}$ "dumping" tra o seu analfabetismo econômico o fato de ele pensar que: "a desmobilização da economia da guerra, depois de 1945, por muito pouco não atirou o excesso de construções e o setor industrial dependente do governo numa nova recessão" 52 . Carson deveria ter sido obrigado a ler o capítulo "A dispersão de tropas e burocratas", de Henry Hazlitt (1894-1993) $)^{53}$. Adiante, ele compra a opinião que considera o "lucro obtido pelo monopólio como um excedente tirado ao consumi-

\footnotetext{
${ }^{46}$ CARSON. Studies in Mutualist Political Economy, p. 246.

${ }^{47}$ Ora, tanto quanto algo pode ser voluntário, dado que a relação patrão-empregado é, necessariamente, uma relação de espoliação e exploração.

${ }^{48}$ CARSON. Studies in Mutualist Political Economy, p. 254.

${ }^{49}$ Idem. Ibidem, p. 265.

${ }^{50}$ Idem.

${ }^{51}$ Idem. Ibidem, p. 303.

52 Idem. Ibidem, p. 257.

${ }^{53}$ HAZLITT, Henry. Economia em Uma Única Lição. São Paulo: Instituto Ludwig von Mises Brasil, 2010.
} 
dor, no processo de troca"54. Isso é bastante razoável em se tratando do monopólio produzido pelo capitalismo monopolista do estado corporativo; nele, algumas firmas são proibidas de entrar no mercado, enquanto as demais, privilegiadas, podem explorar os consumidores. Mas, diabos! Como isso pode acontecer no sistema do capitalismo laissez-faire, no qual lucros adicionais, supostamente obtidos pelos "monopolistas", hão de atrair para a indústria outros empresários, assim como o mel atrai as abelhas? Com efeito, todo comércio no sistema de livre iniciativa pura é mutuamente benéfico no sentido ex ante, e não há exploração.

Mais analfabetismo econômico:

Ainda assim, Stromberg atribui um valor bastante exagerado às vantagens da produção em larga escala no livre mercado. Em quase todas as formas de produção, exceto em algumas poucas, o máximo da economia de escala é obtido num nível relativamente baixo de produção. Na agricultura, por exemplo, um estudo do USDA [Departamento de Agricultura dos Estados Unidos] descobriu, em 1973, que a economia de escala foi maximizada com o modelo de fazenda mecanizada administrada por um só homem [fully-mechanized one-man farm $]^{55}$.

É mais do que curioso o fato de Carson depositar tanta fé num estudo do USDA. Parece-me que outsiders, como os burocratas, o USDA e o próprio Carson, não podem jamais determinar o tamanho ótimo das firmas, que presumivelmente está sempre mudando. É o mercado que o faz. Sem subsídios governamentais, sem favorecimentos, sem regulações e outras intervenções, tal como seria no capitalismo laissez-faire, o melhor porte das empresas é aquele em que elas possam sobreviver e prosperar $^{56}$. Trata-se de uma

\footnotetext{
${ }^{54}$ CARSON. Studies in Mutualist Political Economy, p. 266.

${ }^{55}$ Idem. Ibidem, p. 305.

56 STIGLER, George. Economies of Scale. Journal of Law and Economics, Vol. 1 (1958): 54-71.
}

questão empírica que não se harmoniza com pronunciamentos ${ }^{57}$ como os de Carson.

$\mathrm{Na}$ visão do nosso autor, grandes dimensões são uma coisa ruim ${ }^{58}$. Mas só o mercado pode determinar o quão grande é ser grande demais. E, se uma firma ultrapassar essa barreira, independentemente de qual seja esta, as forças do mercado não tardarão a tomar as rédeas. Empresas como Microsoft, Wal-Mart, Coca-Cola e McDonald's são de fato colossais. Mas isso significa que são grandes demais? Nem um pouco. Se fosse assim, estariam agora em busca de reduzir seu porte; seus competidores atentariam para isso. Futuramente talvez seja esse o caso, e assim podemos contar com o encolhimento delas. $\mathrm{E}$ também não é fácil ver como o governo as ampara atualmente ${ }^{59}$. Ora, se algo há, parece que é justamente o contrário. Não é preciso ser um randiano do tipo que lê "America's Persecuted Minority: Big Business" ${ }^{\prime \prime 0}$ para divisar algumas firmas de mercado verdadeiras, mesmo no pântano de regulação governamental que ora nos aflige.

É hora de levar este artigo a seu termo. O livro de Carson é interessante, e até mesmo fascinante, mas, em última análise, desapontador. Em determinadas questões, Carson acerta na mosca. Em outras, ele está longe, bem longe, em alguma espécie de Terra do Nunca marxista. Talvez a série de críticas de livros da qual este artigo faz parte possa ajudar a trazê-lo de volta à realidade - isto é, à realidade do capitalismo laissez-faire de livre iniciativa.cos

\footnotetext{
${ }^{57}$ N. do T.: O autor emprega a expressão em espanhol, remetendo às proclamações e aos manifestos de grupos revolucionários.

${ }^{58}$ CARSON. Studies in Mutualist Political Economy, p. 322, p. 324.

${ }^{59}$ À parte não pôr na cadeia todos os diretores dessas empresas pelo "crime" de empregar trabalhadores. Está bem, está bem; o governo protege as patentes e os copyrights da Coca-cola. Conte-me outra!

${ }^{60}$ RAND, Ayn. Capitalism: The Unknown Ideal. New York: Signet Books, 1966.
} 